\title{
Dynamic simulation of pellet induration process in straight-grate system
}

\author{
Mansoor Barati \\ Version Post-print/Accepted Manuscript \\ Citation Barati, Mansoor. 2008. "Dynamic Simulation of Pellet Induration \\ (published version) Process in Straight-Grate System." International Journal of Mineral \\ Processing 89 (1-4): 30-39. DOI: 10.1016/j.minpro.2008.09.008 \\ Copyright/License \\ (c) (1) $€$ This work is licensed under the Creative Commons \\ BY NC ND Attribution-NonCommercial-NoDerivatives 4.0 \\ International License. To view a copy of this license, visit \\ http://creativecommons.org/licenses/by-nc-nd/4.0/.
}

How to cite TSpace items

\begin{abstract}
Always cite the published version, so the author(s) will receive recognition through services that track citation counts, e.g. Scopus. If you need to cite the page number of the author manuscript from TSpace because you cannot access the published version, then cite the TSpace version in addition to the published version using the permanent URI (handle) found on the record page.
\end{abstract}

This article was made openly accessible by $U$ of $T$ Faculty. Please tell us how this access benefits you. Your story matters. 


\title{
Dynamic Simulation of Pellet Induration Process in Straight-Grate System
}

\author{
Mansoor Barati, Assistant Professor \\ Dept. of Materials Sci. \& Eng., \\ University of Toronto, WB140 - 184 College Street \\ Toronto, ON, Canada M5S 3E4 \\ Tel: (416)978-5637, Fax: (416)-978-4155,
}

Email: mansoor.barati@utoronto.ca

\begin{abstract}
$\underline{\text { Abstract }}$
A mathematical model of pellet induration process in the straight-grate system is presented. The important physical and chemical phenomena known to affect the heat and mass transfer in the process have been taken into account in the formulation of the model. These include heat transfer between gas and pellet, gas flow, evaporation and condensation of moisture, oxidation of magnetite, combustion of coke breeze, calcination of lime and dolomite, and shrinkage of pellet and pellet bed slump. The model is validated by comparing its predictions against actual measurements in an industrial scale plant as well as a pilot pot grate. The effect of several process parameters on the induration regime are evaluated using the model. It is demonstrated through a case study that the model can be employed as a valuable tool for such purposes as process optimization and design of the induration machine.
\end{abstract}

Keywords: mathematical modeling, pellet induration, straight grate, pellet shrinkage, iron ore pelletizing 


\section{INTRODUCTION}

Production of pellet as a desirable feedstock for ironmaking furnaces has exceeded $300 \mathrm{Mt}$ per year in 2005, accounting for about $24 \%$ of the iron ore processed globally (UNCTAD, 2006). The production of iron ore pellets involves two major steps, forming the "green" pellets in rotary disks or drums, followed by their heat hardening them subsequently at elevated temperatures around 1200 to $1400{ }^{\circ} \mathrm{C}$ to increase the pellet strength.

The heat hardening or "induration" of pellets employs one of the three conventional furnace types: vertical shaft furnace, grate-kiln system, and travelling straight grate. The latter process that was primarily developed by Lurgi and is currently owned by OutoKumpu Technology, accounts for two thirds of the world's installed pelletizing processes capacity. This study is focused on simulation of pellet induration process in the straightgrate system.

\section{Description of Induration Process in Straight-Grate Machine}

Fig. 1 depicts schematic of a typical straight-grate induration system. The grate bars fixed on a moving strand are first covered with a layer of burnt pellet, known as hearth-layer. The green pellets containing 7 to 9 wt pct free moisture and 10 to $14 \mathrm{~mm}$ in size are then fed onto this layer and travel together with the sub-layer through several thermal zones of the furnace. The role of the heart layer pellets is to act as a neutral heat absorbing media and protect the grate bars from excessive gas temperatures. The induration process in travelling grate typically consists of four distinct phases: drying, preheating, firing, and cooling. The first stage of drying is updraft to prevent condensation of water and consequential pellet deformation in the bottom layers of the pellet bed. Drying is continued in a subsequent downdraft stage by relatively hot gases coming from firing zone of the furnace. The rate of heat transfer and moisture removal has to be controlled in a certain range, as otherwise spalling may occur. In the preheating phase, pellets are heated to about $1000{ }^{\circ} \mathrm{C}$ by downdraft gas flowing through the bed. Hot gas is typically recycled from cooling zone and augmented with auxiliary heat from hood burners, if required. During this phase, pellets are completely dried and reactions such as decomposition of carbonates (e.g. lime, dolomite), magnetite oxidation and coke combustion take place. The reactions continue in the firing stage, where the gas temperature is raised to $\sim 1350{ }^{\circ} \mathrm{C}$. The strength of the pellets increases at this stage because of recrystallization, sintering and formation of partially liquid phases. The pellet porosity on the other hand is decreased. Temperature and flowrate of gas together with the duration of the firing phase have to be controlled with care to produce pellets of high strength and adequate porosity. Some of the off-gas from the firing zone is recuperated to the drying zone after mixing with air. The remaining of the gas is vented off through the stack.

The induration zone of the furnace is generally divided into several sections and the gas flow rate through each section is controlled by a separate fan. This is intended to provide the operator with the flexibility of controlling the heating profile for better pellet quality and grate bar protection. After firing, burnt pellets undergo cooling where ambient air is drawn upward through the bed. The hearth layer prevents a severe thermal shock to the pellets by preheating the air. The off-gas leaving early stage of cooling has a temperature around $1000{ }^{\circ} \mathrm{C}$. The gas is directed to the firing and preheating zones where is it further heated by the burners. The gases from the later stages of cooling have lower temperature, hence they are used for drying of pellets.

\section{$<<$ Fig. 1 is inserted here $>$}

It is clear from the description of the process that considerable attention has been paid to enhancing the energy efficiency of the overall process. Numerous advancements have been made that enable the operators to alter the process conditions (e.g. gas flow and temperature, grate speed, etc.) and achieve both high pellet quality and low energy consumption. However, optimization of thermal treatment of pellet is inherently an iterative process and determination of the optimum operating conditions in a working plant is extremely difficult, time consuming and costly. Besides, the measurement of critical process data such as temperature within the pellet bed is virtually impossible. As a result, induration processes have traditionally relied on laboratory pot grate test results for determination of optimum design and operating parameters. However, results of a single pot grate experiment are deficient in making distinction between the effects of different variables on the heating profile and pellet quality. On the other hand, a complete study of the effect of even one variable on the process requires numerous experiments, with other variables kept unchanged. Also, pilot tests do not directly provide information on local 
interactions, reactions rates and heat and material balance. As a complementary, and sometimes alternative, method of process analysis, mathematical modeling has been put forward (Young, 1963) soon after the pelletizing technologies came on stream.

\section{Previous Models of Pellet Induration in Straight-Grate Machine}

The original works on calculation of temperature profile in moving pellet beds date back to over four decades ago. Early studies on a purely theoretical approach to modeling of process by Hasenack et al. (1975) and Voskamp and Braz (1975) presented a significant insight into the details which have to be considered. Hasenack et al. took into account convective heat transfer as well as conduction resistance within each pellet. In their calculations, they omitted to consider calcination of carbonates as well as oxidation of carbon since they used non-fluxed pellet with no addition of carbonaceous materials. They collected very valuable information from an operating plant and showed that their model provided satisfactory agreement with the measurements. Voskamp and Braz assumed that the temperature gradient inside each pellet is negligible. They further approximated thermal properties of gas, pellet and grate bar with constant values in each furnace zone.

Following these pioneers, a substantial number of models have been put forward for iron ore sintering (Cumming and Thurlby, 1990, Young, 1977), and pellet induration in shaft furnaces (Norgate et al., 1985)', grate-kiln system (Cross and Young, 1976, Davis and Englund, 2003, Pape et al., 1976, Thurlby, 1988a, 1988b, 1988c, Young et al, 1979), and travelling grate machine (Drugge, 1979, 1981, Breitholtz and Hillberg, 1980, Thurlby, 1979). Several authors have also simulated pellet induration in pot grate (Kucukada et al., 1994, Seshadri and da Silva Pereira, 1985). Wynnyckyj and Batterhamt (1985) have presented a comprehensive review of the physical and chemical phenomena pertaining to sintering and pellet firing and the approaches towards modeling of such phenomena.

Despite the considerable studies on modeling of these processes and pellet induration in particular, only a few have developed a model for straight-grate induration process consisting of complete drying, firing and cooling cycles. In addition, each model has been developed by taking into account a few of many reactions and physical changes involved. One phenomenon that is generally overlooked, yet plays a significant role in the process performance, is variations of pellet porosity and corresponding bed shrinkage as the pellet bed passes thorough different thermal zones of the furnace. The present article describes development and validation of a complete mathematical model for pellet induration by the straight-grate method. The major improvement over the previous studies in this area are first, including all important reactions in the model and second, taking into account pellet shrinkage and the resulting pellet bed slump as they undergo the thermal treatment. The model is based entirely on the existing knowledge pertaining to physical and chemical changes in the pellet induration process.

\section{MATHEMATICAL MODEL}

The mathematical model is developed to predict the detailed process information including temperature, flowrate and composition of gases, rate and extent of progress for the reactions, porosity and chemical composition of pellet, and bed slump at any position and in different times. In the formulation of the model, the following phenomena have been taken into account.

i. Heat transfer between pellet and gas with temperature and composition dependent thermophysical properties for both phases

ii. Evaporation and condensation of moisture

iii. Oxidation of magnetite

iv. Calcinations of limesote $\left(\mathrm{CaCO}_{3}\right)$ and dolomite $\left((\mathrm{Ca}, \mathrm{Mg}) \mathrm{CO}_{3}\right)$

v. Combustion of carbon (e.g. coke breeze)

vi. Reduction in pellet porosity and the corresponding bed shrinkage

Certain assumptions with acceptably small impact on the accuracy of calculations were made. These include

i. The induration process is at steady state conditions

ii. Gas distribution through the pellet bed is uniform, i.e. no channeling of the gas occures

iii. The thermal conductivity of individual pellets is infinitely high so that temperature gradient within each pellet can be neglected 
iv. The pellet bed is represented as a porous packed bed of uniformly sized spheres

$\mathrm{v}$. Vertical gas velocity is much greater than the horizontal grate speed

vi. Heat conduction within the pellet bed is insignificant relative to the convective gas-solid heat transfer rate

vii. Heat losses are limited only to the initial heat storage in the grate bars

viii. Heat released/absorbed by the chemical reactions is solely exchanged with the solids, except the heat of moisture condensation that is split equally between gas and solid.

The equations forming the mathematical model are presented below. The definition of all symbols is provided in nomenclature at the end of the paper. Some thermokinetic properties and constants that have been used in the model development are given in the appendix.

\section{A. Heat Transfer}

The dominant heat transfer mechanisms are conduction and radiation between gas and pellet. Using an effective heat transfer coefficient $(h)$ that contains the contribution of radiation, the governing equations are given by:

$$
-G C_{g} \frac{\partial T_{g}}{\partial z}=h A\left(T_{g}-T_{p}\right)+\sum\left(1-\alpha_{i}\right) R_{i} \Delta H_{i}
$$

for the gas phase, and

$$
\rho_{b} C_{p} \frac{\partial T_{p}}{\partial z}=h A\left(T_{g}-T_{p}\right)-\sum \alpha_{i} R_{i} \Delta H_{i}
$$

for the pellets. The gas and pellet heat transfer area is calculated from:

$$
A=\frac{6\left(1-\varepsilon_{b}\right)}{\phi d_{p}}
$$

In Eqs. [1] and [2], $\alpha_{i}$ is the fraction of heat from $i^{\text {th }}$ reaction, that is retained by the solids. As indicated in the assumptions, $\alpha_{i}$ is set to 0.5 for water vapor condensation and unity for all other reactions. It was noticed that because of high heat transfer coefficient, the heat of reactions is immediately distributed between the two phases, regardless of the initial share of each phase from the heat.

It is evident from Eqs. [1] and [2] that the heat transfer coefficient has a significant contribution to the rate of heat transfer. A wide range of correlations have been put forward by several authors for calculation of the heat transfer coefficient in packed beds. Seshadri and da Silva Pereira (1986) evaluated validity of different heat transfer expressions in predicting the temperature distribution for pellet beds and concluded that Eq. [4] known as the Ranz-Marshall (1952) correlation provides the best agreement between the experimental and the calculated results.

$$
N u=2.0+0.6\left(\frac{R e_{p}}{\varepsilon_{b}}\right)^{1 / 2}(\operatorname{Pr})^{1 / 3}
$$

The coefficient for heat transfer to the grate bar is calculated by the equation presented by Voskamp and Branz (1975)

$$
N u=5(R e)^{1 / 2}
$$

It is important to note that the heat transfer coefficient calculated from these equations has essentially the effect of radiation embedded in, as it has been validated at high temperatures where radiation has an appreciable contribution to the heat exchange.

\section{B. Evaporation and Condensation of Moisture}

The drying of pellet can be best represented by a three stage model (Cumming and Thurlby, 1990, Seshadri and da Silva Pereira, 1986). In this model, before the pellet water content reaches a critical concentration, the rate of drying is controlled by mass transfer from the pellet surface to the gas bulk. The rate expression for this stage is presented as: 


$$
R_{w}=k_{w} A\left(w_{g}^{e}-w_{g}\right)
$$

where the mass transfer coefficient, $k_{w}$, can be derived from a correlation similar to that of heat transfer coefficient (Keey, 1972, Perry, 1973) as:

$$
k_{w}=\frac{D_{H_{2} O}}{d_{p}}\left[2.0+0.6\left(\frac{R e_{p}}{\varepsilon_{b}}\right)^{1 / 2}(S c)^{1 / 3}\right]
$$

The saturation water vapor pressure of the gas, $w_{g}^{e}$, is calculated from the equilibrium conditions at the pellet surface temperature. The diffusivity of water vapor thorough the gas phase can be obtained from the correlation provided by Fuller et al. (1966).

$$
D_{\mathrm{H}_{2} \mathrm{O}}=\frac{1.2 \times 10^{-9} T_{g}^{1.75}}{P^{\prime}}
$$

The value of critical moisture content was assumed to be $120 \mathrm{~kg} / \mathrm{m}^{3}$ (Hasenack et al., 1975, Voskamp and Brasz, 1975).

In the second step of drying, when the pellet humidity drops below the critical concentration, an evaporation front penetrates toward the pellet centre and pore diffusion within the dry shell begins to play role as the rate limiting step. A mixed control model consisting of two resistances, diffusion thorough the dry shell and mass transfer in the gas phase, may be used to express the drying rate as:

$$
R_{w}=\frac{A\left(w_{g}^{e}-w_{g}\right)}{\frac{1}{k_{w}}+\frac{r_{p}\left(r_{p}-r_{w}\right)}{2 r_{w} D_{H_{2} O}^{e}}}
$$

where $D_{\mathrm{H}_{2} \mathrm{O}}^{e}$ is the effective diffusion coefficient of water vapor through the pellet pores and is calculated from the following correlation (Perry, 1973):

$$
D_{\mathrm{H}_{2} \mathrm{O}}^{e}=D_{\mathrm{H}_{2} \mathrm{O}} \frac{\varepsilon_{p}}{\tau}
$$

with tortuosity $(\tau)$ related to the pellet porosity $\left(\varepsilon_{p}\right)$ via (Perry, 1973):

$$
\tau=\varepsilon_{p}^{-0.41}
$$

Towards the end of drying, the evaporation rate is controlled by heat transfer from the gas to the pellet and is represented by:

$$
R_{w}=\frac{h A\left(T_{g}-T_{w}\right)}{\Delta H_{v}} \frac{r_{w}}{r_{p}}
$$

The point of transition between the two latter mechanisms of drying is when the rate of drying in the heat transferred controlled regime becomes smaller than that of the mixed control regime. $T_{w}$ in Eq. [12] is wet bulb temperature and can be calculated through iterative methods (Parsons, 2005) or expressions obtained by regression through the experimental data (Seshadri and da Silva Pereira, 1986),as presented in the appendix.

Condensation of water vapor occurs in the layers of pellet with temperature lower than the saturation temperature of the gas. Eq. [6] presents the rate of condensation as a negative value and the heat of condensation is portioned equally between the gas and the pellets.

\section{Chemical Reactions}

The rates of all chemical reactions including decomposition of carbonates, combustion of coke and oxidation of magnetite are expressed using a topochemical or unreacted shrinking core model (Levenspiel, 1972). In this model, as schematically illustrated in Fig. 2, reaction commences at the pellet surface and progresses toward the centre, leaving behind a shell of reaction products (voidage in case of carbon). 


\section{$<<$ Fig. 2 is inserted here $>>$}

For magnetite oxidation, the reaction consists of three steps: transfer of oxygen from the gas bulk to the pellet surface, pore diffusion through the hematite layer, and interfacial surface reaction with the magnetite particles, i.e.

$$
2 \mathrm{Fe}_{3} \mathrm{O}_{4}+\frac{1}{2} \mathrm{O}_{2} \rightarrow 3 \mathrm{Fe}_{2} \mathrm{O}_{3}
$$

A kinetic model based on mixed control mechanism and applicable to the entire oxidation duration has been proposed by Papanastassiou and Bitsianes (1973a) in the following form:

$$
\frac{d r_{m}}{d t}=\frac{-\left(C_{O_{2}}^{g}-C_{O_{2}}^{e}\right)}{\frac{\rho_{m}}{4}\left[\frac{r_{m}^{2}}{r_{m}^{2} k_{O_{2}}}+\frac{r_{m}^{2}}{D_{O_{2}}^{e}}\left(\frac{1}{r_{m}}-\frac{1}{r_{p}}\right)+\frac{1}{k_{m}^{\prime}}\right]}
$$

where $k_{\mathrm{O}_{2}}$ is the rate of oxygen gas phase mass transfer and is presented by an equation similar to Eq. [7], with $D_{\mathrm{O}_{2}}$ replacing $D_{\mathrm{H}_{2} \mathrm{O}}$. Diffusivity of oxygen can be calculated from the correlation developed by Fuller et al. (1966)

$$
D_{O_{2}}=\frac{9.2 \times 10^{-10} T_{g}^{1.75}}{P^{\prime}}
$$

$k_{m}^{\prime}$ in Eq. [14] is the first order rate constant for magnetite oxidation which can be calculated from the correlations gathered from literature and provided in the appendix.

An expression similar to Eq. [14] is valid for the rate of carbon combustion, with the difference being that the equilibrium oxygen concentration is approximately zero in this case.

Calcination of carbonates is controlled only by temperature and can take place within the entire pellet when it reaches an appropriate temperature. The rate of calcinations of dolomite or limestone is thus expressed as:

$$
R_{l / d}=k_{l / d}^{\prime} m_{l / d}
$$

where $m_{l / d}$ is the concentration of the species of interest. Dolomite is considered to decompose as two separate carbonates $\mathrm{CaCO}_{3}$ and $\mathrm{MgCO}_{3}$.

It must be emphasized that in the reactions sub-model, it is assumed that all of the considered reactions can take place simultaneously with distinct boundaries.

\section{Mass Balance on Gas and Pellet}

The gas flowrate in any section of the machine is chiefly decided by the pressure drop across the bed, which is controlled by the fan draft. The equation proposed by Ergun (1952) relates the pressure gradient and gas flux as:

$$
\frac{\partial P}{\partial z}=\frac{150 \mu_{g}\left(1-\varepsilon_{b}\right)^{2}}{\left(\varnothing d_{p}\right)^{2} \varepsilon_{b}^{3} \rho_{g}} G+\frac{1.75\left(1-\varepsilon_{b}\right)}{\emptyset d_{p} \varepsilon_{b}^{3} \rho_{g}} G^{2}
$$

However, as the gas exchanges mass with solids through evaporation/condensation or other reactions, the quantity and compositions of both phases change with time and position. The changes in the gas flowrate and concentration of individual gas species are related to the rate of reactions via Eqs. [18] and [19].

$$
\begin{aligned}
& \frac{\partial G}{\partial z}=\sum-R_{i} \\
& \frac{\partial w_{i}}{\partial z}=-\frac{R_{i}}{v_{g}} B_{i}
\end{aligned}
$$

$B_{i}$ in Eq. [19] is an stoichiometric coefficient relating the changes in the mass of the reacting gas species to that of the solid thorough the corresponding reaction $i$. ( 1 for water, 32/928 for magnetite oxidation and so on). $v_{g}$ is the superficial gas velocity and is calculated from: 


$$
v_{g}=\frac{G}{\rho_{g}}
$$

Concentration of pellet constituents also changes according to:

$$
\frac{\partial w_{j}}{\partial t}=-R_{i} \frac{1}{\left(1-\varepsilon_{b}\right)}
$$

\section{E. Pellet and Bed Shrinkage}

Gas flowrate and temperature profile of the pellet bed is strongly influenced by the compactness and the height of the pellet bed. The previous models of pellet induration in straight-grate have been developed on the assumption that the pellet bed height remains constant during the process. However, it is well known that the pellet porosity decreases significantly after firing due to formation of semi-liquid slag phase and more importantly, due to solid state sintering (Wynnyckyj and Fahidy, 1974). It is important to consider in the model formulation the changes in the pellet physical properties and their impact on the heat and mass transport phenomena.

Wynnyckyj and Fahidy (1972) have indicated that the shrinkage of pellet is a thermally activated process and can be related to the firing time and temperature as

$$
\frac{\beta}{1-\beta}=\frac{V_{0}-V_{t}}{V_{p}-V_{t}}=k_{s} t^{n}
$$

This equation can be rearranged and differentiated to provide the rate of change in the pellet volume as:

$$
\frac{d V_{p}}{d t}=\frac{n k_{s} t^{n-1}}{1+k_{s} t^{n}}\left[V_{t}-\frac{V_{0}+V_{t} k_{s} t^{n}}{1+k_{s} t^{n}}\right]
$$

For a commercial iron ore concentrate, regression analysis of their experimental data yields the following expressions for $k_{s}$ and $n$.

$$
\begin{gathered}
k_{S}=3.3 \times 10^{21} \exp \left(\frac{-77000}{T}\right) \\
n=13.1850-1.58622 \times 10^{-2} T+4.88318 \times 10^{-6} T^{2}
\end{gathered}
$$

The porosity of pellet as a function of time is calculated from temperature history of the pellet. At any new time (and temperature), first an equivalent "time at temperature", $t_{e}$, is calculated from Eq. [22]. This time is then substituted into Eq. [23] to calculate the rate of volume change and the new volume for the pellet. Using this value and the initial volume, the porosity can then be determined.

The decrease in the pellet porosity gives rise to the pellet shrinkage which in turn affects the characteristics of the bed such as its height and void fraction. Hoffman and Finkers (1995) have presented a model that relates the bed void fraction to density, size distribution and sphericity of the randomly packed particles. This model, shown in Eq. [26] has been validated for a very wide range of particle sizes and is used here to discuss the effect of pellet size on the bed voidage.

$$
\varepsilon_{b}=1-\left\{1-\left[0.68 \exp \left(-0.0371 \rho^{\prime}{ }_{p} d_{p}^{\prime}\right)+0.32\right] \exp (-1.72 \sigma)\right\} \emptyset^{0.848}
$$

It can be demonstrated by using Eq. [26] that in the range of pellet size $(10-14 \mathrm{~mm})$ and density $(\sim 3000$ $\mathrm{kg} / \mathrm{m}^{3}$ ), and with the reduction in the pellet diameter being typically less than $10 \%$, the changes in the bed void fraction are not considerable in the induration process. This is in agreement with other findings, showing that the bed void fraction is not significantly increased after firing. For example Wynnyckyj and Batterham (1985) have discussed from an unpublished work of Thurbly that the bed voidage of 0.37 for green bed increased to 0.39 after induration. It is therefore reasonable to assume that the effect of pellet shrinkage on the bed void fraction is negligible and it primarily gives rise to the bed slump. The bed height is thus related to the pellet porosity through: 


$$
H=H_{s l}+H_{0} \frac{1-\varepsilon_{p}}{\varepsilon_{b}^{\circ}}
$$

\section{NUMERICAL SOLUTION PROCEDURE}

A computer program coded in Visual Fortran (Intel) and called INDMOD was developed for numerical solution of the described equations. Initially, the operating parameters of the system are set. These include pellet properties (size, sphericity, porosity, composition, moisture content), induration machine parameters (length and speed of the grate, lengths of various zones), and operating conditions (pressure drop and on-gas temperature in various cycles, bed porosity).

For solving the differential equations, a finite different scheme is used. The bed of pellets is divided into several segments, forming a column of elements. The vertical spacing of the elements is set to an initial value of $0.1 \mathrm{~cm}$ for the beginning of the process but is decreased corresponding to reduction in the bed height as the temperature increases and the pellet undergoes shrinkage. The total process time is divided to one second time intervals to ensure the stability of the solution and accuracy of the results. The differential equations are discretized with respect to the distance (height) and time and are solved subsequently. The calculations are made on nearly one million nodes for the base case of pellet bed height and grate speed. It was realized that for larger elements, the convergence may not be reached under some conditions such as very small pellets, high rates of reactions, etc. The program was run on a $2.4 \mathrm{GHz}$ personal computer with the calculation time being normally 1 to 3 minutes.

Integration of the discretized equations over the elements requires determination of the gas flowrate in each element. Generally, the pressure drop measurements are more reliable and readily available than the gas flowrates. Therefore, it was decided to set the pressure drop as an input parameter and calculate the gas flowrate using Eq. [17]. However, this approach requires iteration as the gas flowrate is dependent on the reactions rates and thus on temperature distribution. The approach toward simultaneous calculation of flowrate and temperatures is shown in Fig. 3. An estimate of the gas flowrate is first calculated via Eq. [17]. This flowrate is assigned to the first element of the column and the differential equations are solved to yield temperatures and the reactions rates. The exit gas flowrate and pressure drop across the element are then calculated using Eqs. [18] and [17] respectively. Thermodynamic and thermophysical properties of the gas and pellet are recalculated at the newly obtained temperatures and substituted back in the same equations. This process is repeated until the temperatures for two consecutive iterations agree to an acceptable accuracy. Calculations are then continued for the next elements in the column until the flowrates and pressure drops for all elements are obtained. The total pressure drop across the bed is then calculated by summing all pressures losses. This value is compared with the measured $\Delta \mathrm{P}$ across the bed and if the error is adequately low, the calculations are continued for the next time step. Otherwise, the initially estimated flowrate is adjusted proportional to the difference between the calculated and measured pressure drops and the calculations are repeated using this updated flowrate as the starting value.

$<<$ Fig. 3 is inserted here $>>$

\section{MODEL VALIDATION}

A complete validation of the model requires collecting data from an operating plant under steady state conditions. Measuring temperature inside a moving bed and away from the side bars (to avoid effect of heat losses) is rather impractical. Therefore, temperature predictions were validated against measurements in a pilot pot-grate induration facility. The experiments were carried out in the pilot unit of pellet plant at Mobarakeh Steel Company (MSC). The pilot facility consists of a rotating disk for producing green pellets and a cylindrical pot furnace with an inside diameter of $26 \mathrm{~cm}$ and a height of $50 \mathrm{~cm}$. Typically, for each experiment, $10 \mathrm{~cm}$ of fired pellets are loaded onto the bottom plate of the pot and the pot is filled with green pellets to a desired height, usually $35 \mathrm{~cm}$. Five thermocouples, identified as T1 to T5 are positioned on top of the pellet bed, $5 \mathrm{~cm}, 25 \mathrm{~cm}$, $35 \mathrm{~cm}$ below the surface, and $5 \mathrm{~cm}$ below the bottom plate (in the gas duct), respectively. Pressure drop across the bed and temperature readings are logged continuously during the induration test. The details of measurements and also a mathematical model for the pot-grate are discussed in a separate publication (Barati, 2008). 
The results are shown in Fig. 4. As seen, the model generated data coincide very well with the measurements. There are slight deviations between the thermocouple readings and the calculated values particularly at high temperatures. This can be mainly due to the fact that at high temperature, the radiation losses from the bed surface and the pot grate wall become significant, while this has not been taken into account in the model calculations. Moreover, the error in the thermocouple readings caused mainly by inaccurate positioning can be in the order of deviations between the two values.

\section{$<<$ Fig. 4 is inserted here $>>$}

The model of straight-grate was further validated against gas flow measurements reported by Hasenack et al. (1975). They measured the gas flowrates of an operating plant in the gas ducts by pitot tubes. The input parameters to the model such as gas temperature and pressure drops were extracted from their paper and the gas flowrate was calculated. Since the model provides the gas flowrate through the bed and not for the measurement points (in the ducts), the ingress flowrate, estimated by Hasenack et al., were added to the model predictions to arrive at the total predicted flow. The results of calculations are compared with the measurements in Table 1. As can be seen, the model calculations are within $10 \%$ of the measured values. Bearing in mind that the calculations of gas leakage and also flow measurements by pitot tube are subject to a few percent error each, the predicted flowrates are considered well consistent with the actual values.

$<<$ Table 1 is inserted here $>$

\section{SIMULATION RESULTS AND DISCUSSION}

All the input parameters to the model including arrangement of various zones, feed characteristics and operating conditions may be changed individually or together to study their effect of these variables on the process performance. Each time the model is run, the following information are calculated and recorded for every element within the pellet bed

- Temperatures of gas and solid

- Chemical composition of pellet and gas

- Rate of reactions and moisture condensation/evaporation

- Flowrate and pressure of gas

- Porosity of pellet and height of the pellet bed

In this article, results obtained from varying only a few of the input parameters are discussed. The process characteristics used as the base case simulation are shown in Table 2.

<<Table 2 is inserted here>>

\section{A. Effect of the Pellet Characteristics}

The drying regimes of pellet in different depths of the bed are shown in Fig. 5. It is seen that the drying of pellets in the middle of the bed requires longer time than those in the top and bottom layers. However, some condensation takes place in the top layer during updraft drying stage. The entire pellet bed is dried within the first 10 minutes of the process. The drying times calculated using the model agree well with the measurements of Seshadri, and da Silva Pereira (1985), showing that depending on the position in the bed and on-gas temperature, drying will require about 5 to 10 minutes to complete.

\section{$<<$ Fig. 5 is inserted here $>>$}

Shape and size of pellet have significant impacts on heating and drying regimes. Fig. 6 illustrates the effects of pellet size and sphericity varied between some arbitrary selected values on the maximum pellet temperature. It is palpable that more spherical and larger pellets facilitate gas passage and enhance the heat transfer, thus give rise to the pellet temperature increase. 


\section{$<<$ Fig. 6 is inserted here $>>$}

The pellet porosity is one of the most critical properties affecting both strength of the burnt pellet and its reduction behavior in the downstream ironmaking process. The variations in the pellet porosity were incorporated into the model as discussed previously. Fig. 7 depicts the pellet shrinkage during the thermal treatment that was shown in Fig. 4. It is seen that the pellet porosity of 0.32 for green pellets decreases to 0.22 for the burnt pellets. In this figure, the calculations have been compared with two measurements. In one experiment, the flow of hot gases was stopped during the firing and the pellets were cooled by flowing nitrogen. The porosity was then measured for several pellets from this batch. In other experiment, the induration was completed. As shown, the model predictions are well consistent with the actual measurements, proving that the pellet shrinkage model is capable of reproducing the actual values. The reduction in the pellet porosity, as discussed earlier, gives rise to reduction in the pellet size and bed height. These in turn affect the gas flowrate in two opposing ways; bed slump results in higher gas flowrate (under constant pressure drop) and smaller pellets create more resistance against the gas flow. The balance of the two effects determines the overall impact of the pellet shrinkage on the gas flow rate. Fig. 7 compares gas flowrate for two cases: with and without considering the pellet shrinkage. As can be seen, the overall error introduced by neglecting the pellet shrinkage is relatively small (3 to $4 \%)$.

\section{$<<$ Fig. 7 is inserted here $>>$}

\section{B. Effect of Pellet Chemical Composition}

The favorable effects of magnetite presence in the iron ore feed on more uniform temperature distribution and pellet quality as well as reduction in induration energy consumption have been well recognized and documented. The effect of magnetite content of the pellet on the thermal behavior of the pellet is studied here using the model. Fig. 8 compares the maximum bed temperature for the base case (40 wt $\%$ magnetite) and magnetite pellets (95 $\mathrm{wt} \%$ ). It is seen that the temperatures of the bed upper layers are not considerably influenced by the heat release associated with the magnetite oxidation. On the other hand, a substantial temperature rise is realized in the bottom layers of the bed, because the heat is gradually built up in the gases flowing downward and exchanged more vigorously with the deep layers of pellet. The magnetite oxidation, hence gives rise to a more uniform temperature distribution, which in turn reduces the variations in the quality of the produced pellets.

\section{$<<$ Fig. 8 is inserted here $>>$}

A similar improvement in the heating regime is achieved by addition of carbon bearing materials to the pellet feed (Appleby and Shaw, 1985, Audet et al., 2003). Fig. 9 depicts the effect of carbon addition on the temperature variations in the pellet layer on top of the heart layer. Typically, the pellets in this depth do not receive sufficient heat and the final pellet strength is lower than those in the upper layers. It is well evident from Fig. 9 that addition of carbon increases the maximum temperature together with the period the pellets remain at this temperature. The strength of pellet from layer thus should be enhanced substantially by addition of a proper amount of carbon.

\section{$<<$ Fig. 9 is inserted here $>>$}

One of the great advantages of using simulation tools in process analysis is giving insight into the details of different phenomena from several perspectives. Combustion of carbon, for instance, may be visualized by presenting the variations in the oxidation rate, carbon content, temperatures or gas composition. As an example shown in Fig. 10, one can clearly determine the onset and duration of the reactions from the changes in the gas oxygen content. The first drop in this figure represents a decrease in the oxygen concentration because of the increase in water vapor content of the gas. The second valley points to decrease in oxygen content by the oxidation reactions. It is apparent that the magnetite oxidation ( $0 \%$ carbon case) consumes mcuh less oxygen that then carbon combustion reaction (1\% and 2\% carbon cases). From this figure, it can be concluded that the oxidation reactions begins after the pellet is dried and they take about 5 minutes to complete throughout the bed. 
$<<$ Fig. 10 is inserted here $>>$

\section{Effect of Multiple Variables}

The model may be employed to investigate effect of several parameters on the induration performance and determine the optimum operation or deign conditions. For example increasing the bed height and pellet throughput is generally limited by two factors: disintegration of weak pellets in the bottom layers due to static load of the bed, and inadequate heat supply to the same layers during firing. While the disintegration problem may be mitigated by appropriate choice of binder type and content, additional heat can be provided to the bottom layers by addition of coke breeze as an auxiliary heat source. This scenario has been examined using the model and the results are presented in Fig. 11. The bed height was increased to $55 \mathrm{~cm}$ and the temperature profile was calculated for two cases, without carbon and 1\% carbon addition. Fig. 11 compares the temperature of the pellet bed in $35 \mathrm{~cm}$ depth for the two situations. As seen, in the case of carbon-free feed, the maximum temperature is below $1100{ }^{\circ} \mathrm{C}$, which is insufficient for heat hardening of the pellets. Addition of $1 \%$ carbon however increases the temperature to $1220^{\circ} \mathrm{C}$ for a fairly steady period of about 8 minutes. Therefore, the negative effect of increasing the bed height can be compensated for by carbon addition.

$<<$ Fig. 11 is inserted here $>>$

\section{CONCLUSIONS}

A model of pellet induration process in moving straight grate has been developed. All major reactions and physical changes taking place throughout the process have been incorporated into the model. Comparisons with logged data from an operating plant and direct measurements in a pilot pot grate have indicated that the model predictions are well consistent with the actual values. By simulating several scenarios, it was demonstrated that the model provides insight into the details of the process and can be deployed as a valuable tool for design of the furnace and optimization of the process.

\section{AKNOWLEDGMENT}

The author wishes to thank R\&D department and pelletizing plant of Mobarakeh Steel Company, Mr. R. Saoleimanpour in particular, for financial support of the project and conducting the pilot tests. The contributions by Dr. A. Saidi and Dr. M. Alizadeh are greatly appreciated. 


\section{Nomenclature}

A Gas - pellet apparent contact area $\left(\mathrm{m}^{-1}\right)$

$B_{i} \quad$ Stoichiometric coefficient relating gas consumed/released per unit wt of solids reacted (32/12, 32/928 for magnetite oxidation, and so on)

$C_{g} \quad$ Specific heat of gas $\left(\mathrm{J} \mathrm{kg}^{-1} \cdot \mathrm{K}^{-1}\right)$

$C_{p} \quad$ Specific heat of pellet $\left(\mathrm{J} \cdot \mathrm{kg}^{-1} \cdot \mathrm{K}^{-1}\right)$

$D_{i} \quad$ Diffusivity of component i $\left(\mathrm{m}^{2} \cdot \mathrm{s}^{-1}\right)$

$D_{i}^{e} \quad$ Effective diffusivity of component $\mathrm{i}\left(\mathrm{m}^{2} \cdot \mathrm{s}^{-1}\right)$

$d_{p}^{\prime} \quad$ dimensionless pellet diameter in $\mu \mathrm{m}$ divided by a scale of $1 \mu \mathrm{m}(-)$

$d_{p} \quad$ Pellet diameter (m)

$G \quad$ Superficial gas flowrate $\left(\mathrm{kg} \cdot \mathrm{m}^{-2} \cdot \mathrm{s}^{-1}\right)$

$H \quad$ Pellet bed height (m)

$H_{0} \quad$ Initial height of the raw pellet bed (m)

$H_{s l} \quad$ Height of the heart layer (m)

$h \quad$ Heat transfer coefficient $\left(\mathrm{J} \cdot \mathrm{m}^{-2} \cdot \mathrm{s}^{-1} \cdot \mathrm{K}^{-1}\right)$

$k_{g} \quad$ Thermal conductivity of gas $\left(\mathrm{J}^{\mathrm{m}} \mathrm{m}^{-1} \cdot \mathrm{s}^{-1} \cdot \mathrm{K}^{-1}\right)$

$k_{m}^{\prime} \quad$ First order rate of magnetite oxidation $\left(\mathrm{m} \cdot \mathrm{s}^{-1}\right)$

$k_{l / d}^{\prime} \quad$ First order rate of lime/dolomite decomposition $\left(\mathrm{s}^{-1}\right)$

$k_{c}^{\prime} \quad$ First order rate of carbon combustion $\left(\mathrm{m} \cdot \mathrm{s}^{-1}\right)$

$k_{\mathrm{O}_{2}} \quad$ Mass transfer coefficient in the gas of oxygen $\left(\mathrm{m} . \mathrm{s}^{-1}\right)$

$k_{s} \quad$ Rate constant of pellet shrinkage $\left(\mathrm{s}^{-1}\right)$

$k_{w} \quad$ Mass transfer coefficient in the gas of water vapor $\left(\mathrm{m} . \mathrm{s}^{-1}\right)$

$m_{l / d} \quad$ Concentration of lime/dolomite $\left(\mathrm{kg} / \mathrm{m}^{3}\right)$

$n \quad$ Constant in pellet shrinkage equation (-)

$\mathrm{Nu} \quad$ Nusselt number $\mathrm{Nu}=h d_{p} / k_{g}$

$P \quad$ Gas pressure $(\mathrm{Pa})$

$P^{\prime} \quad$ Gas absolute pressure (atm)

$\operatorname{Pr} \quad$ Prandtl number $\left(\operatorname{Pr}=\mu_{g} C_{g} / k_{g}\right)$

$R e_{p} \quad$ Pellet Reynold's number $\left(R e_{p}=V_{g} \rho_{g} d_{p} / \mu_{g}\right)$

$R_{i} \quad$ Rate of reaction i $\left(\mathrm{kg} \cdot \mathrm{m}^{-3} \cdot \mathrm{s}^{-1}\right)$

$R_{w} \quad$ Rate of water evaporation/condensation $\left(\mathrm{kg} / \mathrm{m}^{-3} \cdot \mathrm{s}^{-1}\right)$

$R_{l / d} \quad$ Rate of decomposition of lime/dolomite $\left(\mathrm{kg} / . \mathrm{m}^{-3} \cdot \mathrm{s}^{-1}\right)$

Sc $\quad$ Schmidt number $\left(S c=\mu_{g} / \rho_{g} D_{i}\right)$

$t \quad$ Time (s)

$T_{g} \quad$ Gas temperature (K) 


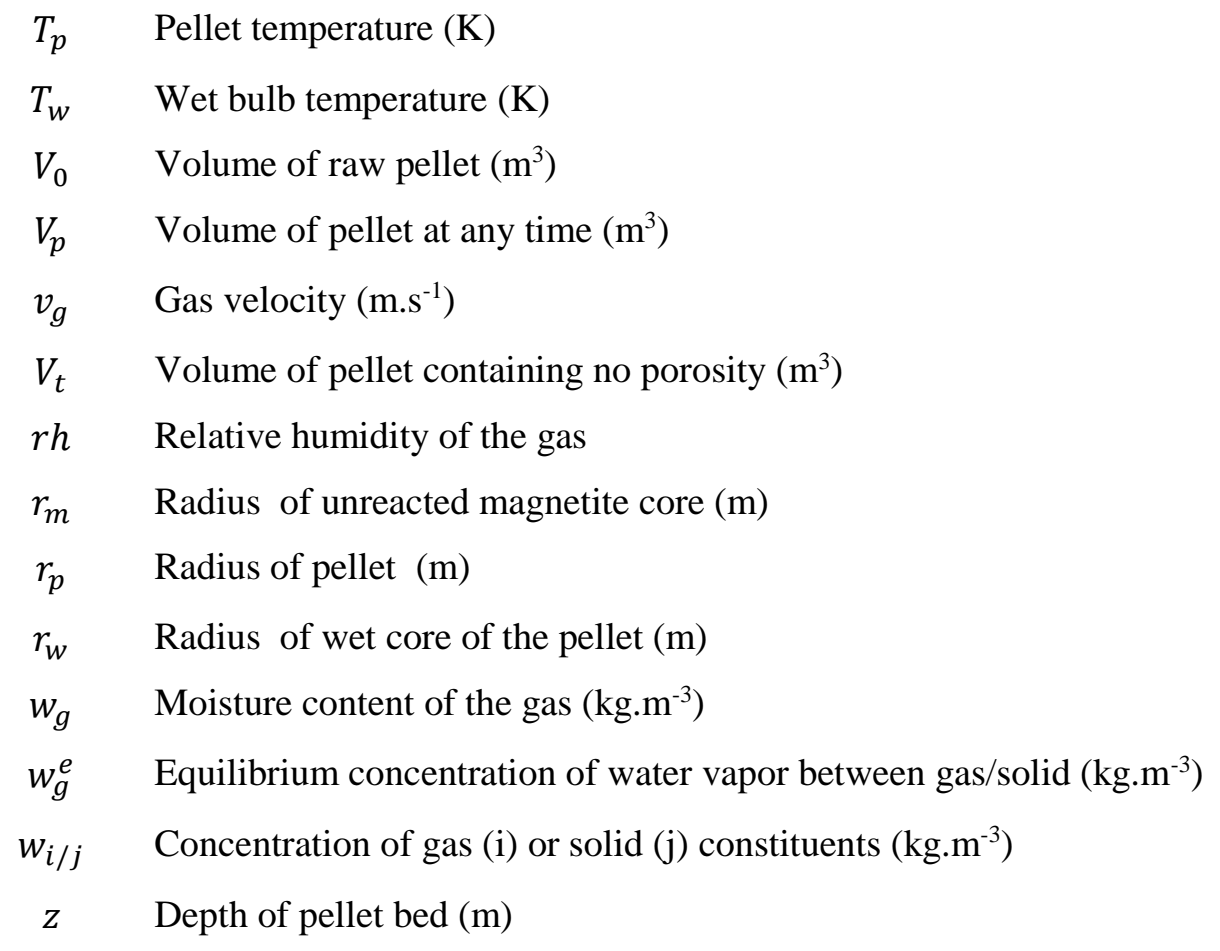

\section{Greek Symbols}

$\alpha_{i} \quad$ Fraction of heat from reaction i, retained by solids

$\varepsilon_{b} \quad$ Void fraction of pellet bed

$\varepsilon_{p} \quad$ Pellet porosity

$\varepsilon_{p}^{\circ} \quad$ Porosity of raw pellet

$\mu_{g} \quad$ Gas viscosity $\left(\mathrm{kg} \cdot \mathrm{m}^{-1} \cdot \mathrm{s}^{-1}\right)$

$\rho_{p}^{\prime} \quad$ Specific gravity of pellet (-)

$\rho_{b} \quad$ Bulk density of pellet bed (wet/dry) $\left(\mathrm{kg} \cdot \mathrm{m}^{-3}\right)$

$\rho_{g} \quad$ Density of gas $\left(\mathrm{kg} . \mathrm{m}^{-3}\right)$

$\phi \quad$ Pellet sphericity

$\Delta H_{i} \quad$ Enthalpy of reaction i $\left(\mathrm{J} \mathrm{kg}^{-1}\right)$

$\Delta H_{v} \quad$ Enthalpy of moisture evaporation/condensation ( $\left.\mathrm{J}^{\mathrm{kg}} \mathrm{kg}^{-1}\right)$

$\sigma \quad$ graphically determined standard deviation of log-normal particle size distribution

$\tau \quad$ Tortuosity 


\section{REFERENCES}

Appleby, J.E., Shaw, G., 1985. Carbonaceous additives in the pelletizing process, in: Capes, C.E. (Ed.), Proc. of $4^{\text {th }}$ Int. Symp. on Agglomeration, Toronto, Canada, 49-74.

Audet, A., Bamrim, A., Dubé, M., Garant, M., Morris, S., Paquet, G., 2003. Reduction of energy consumption in iron ore induration by high utilization of coke breeze, in: Proc. of ISSTech 2003 Conf., Iron and Steel Society, Indianapolis, USA, 103-114.

Barati, M., 2008. Mathematical modeling and validation of pellet induration process in pot-grate, Proc. of AISTech 2008, Pittsburg, USA, May 2008.

Breitholtz, C., Hillberg, C., 1980. Development of a reference model for the drying zone of a travelling grate, in: Proc. of the $3^{\text {rd }}$ IFAC Symp., Pergamon Press, Oxford, England, 415-424.

Cross M., Young, R.W., 1976. Mathematical model of rotary kilns used in the production of iron ore pellets, Ironmaking Steelmaking, 3, 129-137.

Cumming, M.J., Thurlby, J.A., 1990. Developments in modeling and simulation of iron ore sintering, Ironmaking Steelmaking, 17, 245-254.

Davis, R.A., Englund, D.J., 2003. Model and simulation of a ported kiln for iron oxide pellet induration, Can. J. Chem. Eng., 81, 86-93.

Drugge, R., 1975. Modelling of heat exchange phenomena during the induration of magnetite pellets on a moving grate, AIME-SME Preprint No. 75-B-51, AIME-SME, New York, NY.

Drugge, R., 1981. in:Molerus, O., Hufragel, W. (Eds.), Proc. of $3^{\text {rd }}$ Int. Symp. On Agglomeration, Nurenburg, Germany, B36-B57.

Ergun, S.E., 1952. Fluid flow through packed columns, Chem. Eng. Prog. 48, 89-94.

Field, M.A., Gill, D.W., Moragn, B.B., Hawksley, P.G.W., 1967. Combustion of Pulverized Coal, British Coal Utilization Research Association, 186-211.

Fuller, E.N., Schettler, P.D., Giddings, J.C., 1966. New method for prediction of binary gas-phase diffusion coefficient, Ind. Eng. Chem., 58, 19-27.

Hasenack, N.A., Lebelle, P.A.M., Kooy, J.J., 1975. Induration process for pellets on a moving bed, in Proc. Mathematical Process Models in Iron and Steelmaking, Metals Society, 6-16.

Hoffman, A.C., Finkers, H.J., 1995. A relation for the void fraction of randomly packed particle beds, Powder Tech., 82, 197-203.

Keey, R.B., 1972. Drying: Principles and Practice, Pergamon Press, Oxford, UK.

Kucukada, K., Thibault, J., Hodouin, D., Paquet, G., Sylvain, C., 1994. Modeling of a pilot scale iron ore pellet induration furnace, Can. Metall. Q., 33, 1-12.

Levenspiel, O., 1972, Chemical Reaction Engineering, $2^{\text {nd }}$ Ed., John Wiley and Sons, 357-373.

Norgate, T.E., Batterham, R.J., Thurlby, J.A., Povey, B.C., 1985. Development and validation of dynamic and steady state models for the vertical shaft induration of iron ore pellets, in: Capes, C.E. (Ed.), in: Proc. of $4^{\text {th }}$ Int. Symp. on Agglomeration, Toronto, Canada, 721-728.

Papanastassiou D., Bitsianes, Modeling of heterogeneous gas-solid reactions, 1973. G., Metall. Trans., 4, 477486.

Papanastassiou D., Bitsianes, G., 1973. Mechanism and kinetics underlying the oxidation of magnetite in the induration of iron ore pellets, Metall. Trans., 4, 487-496.

Pape, P.O., Frans, R.D., Geiger, G.H., 1976. Magnetite oxidation kinetics and thermal profiles in a magnetite pellet plant cooler, Ironmaking Steelmaking, 3, 138-145.

Parsons, R. (Ed.), 2005. ASHRAE Handbook Fundamentals, ASHRAE, Section 6.9. 
Perry, R.H., Chilton, C.H., 1973. Chemical Engineering Handbook, Tokyo, McGraw Hill, Kogakusha.

Ranz, W.E., 1952, Friction and transfer coefficients for single panicles and packed beds, Chem. Eng. Prog., 48, 247253.

Seshadri, V., da Silva Pereira, R.O., 1985. Mathematical simulation of indurations of iron ore pellets in pot grate, in: Capes, C.E. (Ed.), Proc. of $4^{\text {th }}$ Int. Symp. on Agglomeration, Toronto, Canada,, 729-744.

Seshadri, V., and Pereira, R.O.S., 1986. Comparison of formulae for determining heat transfer coefficient of packed beds, Trans. ISIJ, 26, 604-610.

Thurlby, J.A., Batterham, R.J., Turner, R.E., 1979. Development and validation of a mathematical model for the moving grate induration of iron ore pellets, Int. J. Miner. Proc., 6, 43-64.

Thurlby, J.A., 1988a. A dynamic mathematical model of the complete grate/kiln iron-ore pellet induration process,Metall. Trans. B, 19, 103-112.

Thurlby, J.A., 1988b. Gas flow and pressure balancing in modeling grate/kiln induration, Metall. Trans. B, 19, 113-121.

Thurlby, J.A., 1988c. Energy cost minimization in grate/kiln induration, Metall. Trans. B, 19, 123-132.

UNCTD (United Nations Conference on Trade and Development), 2006. The Iron Ore Market, 2005-2007, Geneva, Switzerland.

Voskamp, J.H., Brasz, J, 1975. Digital simulation of the steady state behaviour of moving bed processes, Meas. Cont., 8, 23-32.

Wynnayckyj, R.J., Fahidy, 1974. Solid state sintering in the induration of iron ore pellets, T.Z., Metall. Trans., 4, 991-1000.

Wynnyckyj, J.R., Batterham, R.J., 1985. Iron ore sintering and pelletizing processes, in: Capes, C.E. (Ed.), Proc. of $4^{\text {th }}$ Int. Symp. on Agglomeration, Toronto, Canada, 957-993.

Young, P.A., 1963. Packed bed in metallurgical operations, in: Proc. of the Symp. on Chemical Engineering in Metallurgical Industries, Institute of Chemical Engineers, 1963.

Young, R.W., 1977. Dynamic mathematical model of sintering process, Ironmaking Steelmaking, 4, 321-328.

Young, R.W., Cross, M., Gibson, R.D., 1979. Mathematical model of grate-kiln-cooler process used for induration of iron ore pellets, Ironmaking Steelmaking, 6, 1-13. 


\section{APPENDIX I. SUPPLEMENTARY EQUATIONS AND CONSTANT USED IN THE MODEL.}

Many correlations for calculations of physical and transport properties and thermokinetics of the reactions were used in the formulation of the model. Thermodynamic properties were calculated using FactSage 5.5 (Ecole Polytechnique). The other expressions and constants used in the current study are provided in this appendix.

$k_{m}^{\prime}= \begin{cases}3.52 \times 10^{8} T \exp \left(\frac{-20073}{T}\right) & T_{p} \leq 657 \mathrm{~K} \\ 1.19 \times 10^{-4} T \exp \left(\frac{-1197}{T}\right) & T_{p}>657 \mathrm{~K}\end{cases}$ (Papanastassiou and Bitsianes, 1973b)

$k_{m}^{\prime}=595.6 T \exp \left(\frac{-17970}{T}\right)$ (Field et al., 1967)

$k^{\prime}{ }_{l}=8.3 \times 10^{6} \exp \left(\frac{-183000}{T}\right)$ (Thurlby, 1988 a)

$k_{d}^{\prime}=2.5 \times 10^{5} \exp \left(\frac{-11200}{T}\right)$ (Thurlby, 1988 a)

$D_{\mathrm{CO}_{2}}=\frac{4.3 \times 10^{-8} \mathrm{~T}_{g}^{1.75}}{\mathrm{P}^{\prime}}$ (Fuller, 1966)

$T_{w}=\left\{\begin{array}{c}173.4-4.166 r_{h}+2.57 \times 10^{-2} r_{h}^{2}+T_{g}\left(0.3648+1.4585 \times 10^{-2} r_{h}-8.688 \times 10^{-5} r_{h}^{2}\right) \quad T_{p}<373 \mathrm{~K} \\ 197.7+125.753 r_{h}-11.64749 r_{h}^{2}+T_{g}\left(0.3964-0.697929 r_{h}+6.31750 \times 10^{-2} r_{h}^{2}\right)+ \\ T_{g}^{2}\left(-2.921 \times 10^{-4}+9.86139 \times 10^{-4} r_{h}-8.5769899 \times 10^{-5} r_{h}^{2}\right) \quad T_{p} \geq 373 \mathrm{~K}\end{array}\right.$

(Seshadri and da Silva Pereira, 1985) 


\section{LIST OF CAPTIONS}

Fig. 1. Schematic diagram of straight-grate pellet induration system

Fig. 2- Schematic of the topochemical reaction progress model

Fig. 3- Comparison between measured and predicted temperature profiles in a pilot induration test

Fig. 4- Drying profile of pellet in different depths of the bed

Fig. 5- Effect of (a) pellet size and (b) pellet sphericity on the maximum pellet temperature

Fig. 6- Variations of pellet porosity with induration time and the effect of pellet shrinkage on the gas flowrate

Fig. 7- Effect of pellet feed magnetite content on the bed temperature profile

Fig. 8- Effect of carbon addition on the temperature profile of pellet layer just above the heart layer

Fig. 9- Oxygen content of the gas versus time in a layer just above the heart layer

Fig. 10- Effect of carbon addition on temperature of pellet layer $45 \mathrm{~cm}$ below the surface of a $55 \mathrm{~cm}$ pellet bed

Table 1- Comparison between measured and calculated gas flowrates of a straight-grate machine

Table 2- Values of process parameters used as the base case of simulation

\section{FIGURES AND TABLES}

Table 1- Comparison between measured and calculated gas flowrates of a straight-grate machine

\begin{tabular}{lccccc}
\hline Process Fan & $\begin{array}{c}\text { Measured } \\
\text { flowrate } \\
\left(\mathrm{Nm}^{3} / \mathrm{s}\right)\end{array}$ & $\begin{array}{c}\text { Estimated } \\
\text { leakage* } \\
\left(\mathrm{Nm}^{3} / \mathrm{s}\right)\end{array}$ & $\begin{array}{c}\text { Calculated } \\
\text { flowrate } \\
\left(\mathrm{Nm}^{3} / \mathrm{s}\right)\end{array}$ & $\begin{array}{c}\text { Total calculated } \\
\text { flowrate }\left(\mathrm{Nm}^{3} / \mathrm{s}\right)\end{array}$ & \% Difference \\
\hline Hood exhaust fan & 116.5 & 40.9 & 81.3 & 122.2 & +4.9 \\
Windbox exhaust fan & 176.0 & 23.9 & 138.3 & 162.2 & -7.8 \\
Updraft drying fan & 126.9 & 17.8 & 98.3 & 116.1 & -8.5 \\
Cooling-air fan & 269.0 & 30.6 & 259.6 & 290.2 & +8.1 \\
\hline
\end{tabular}

* Measurements reported by Hasenack et al. (1975)

**Flowrate through the bed, without taking into account the leakages

Table 2- Values of process parameters used as the base case of simulation

\begin{tabular}{lclc}
\hline Parameter & Value & Parameter & Value \\
\hline Greed pellet bed depth & $35 \mathrm{~cm}$ & Magnetite content & $41 \mathrm{wt} \%$ \\
Sub-layer depth & $10 \mathrm{~cm}$ & Pellet initial moisture & $8.8 \mathrm{wt} \%$ \\
Pellet diameter & $1.3 \mathrm{~cm}$ & Grate width & $4.6 \mathrm{~m}$ \\
Pellet sphericity & 0.95 & Induration time & $40 \mathrm{~min}$ \\
Pellet initial porosity & $32 \%$ & Pellet bed bulk density & $2200 \mathrm{~kg} / \mathrm{m}^{3}$ \\
\hline
\end{tabular}




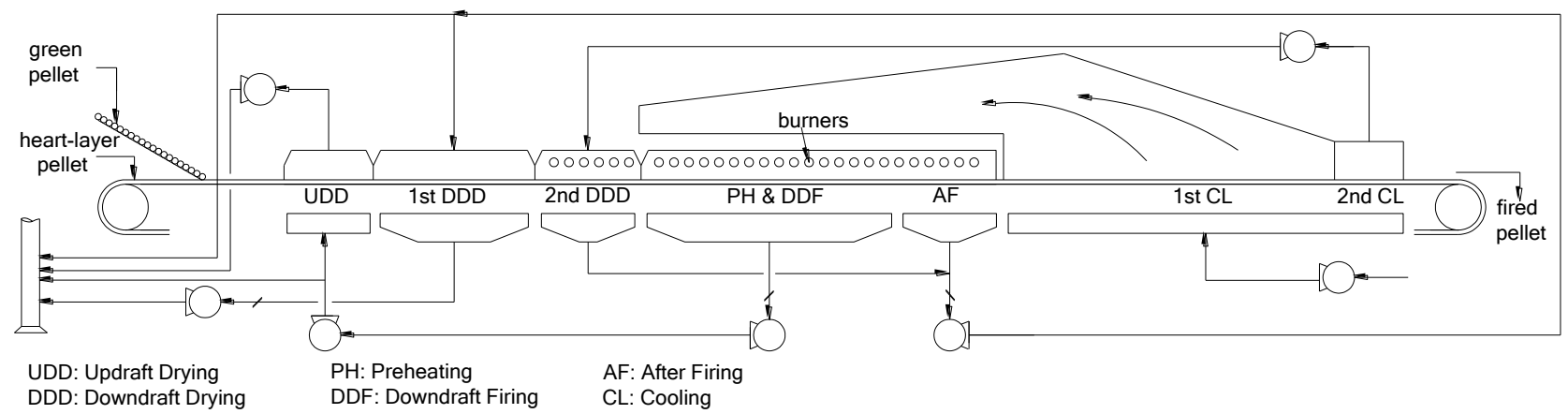

Fig. 1. Schematic diagram of straight-grate pellet induration system

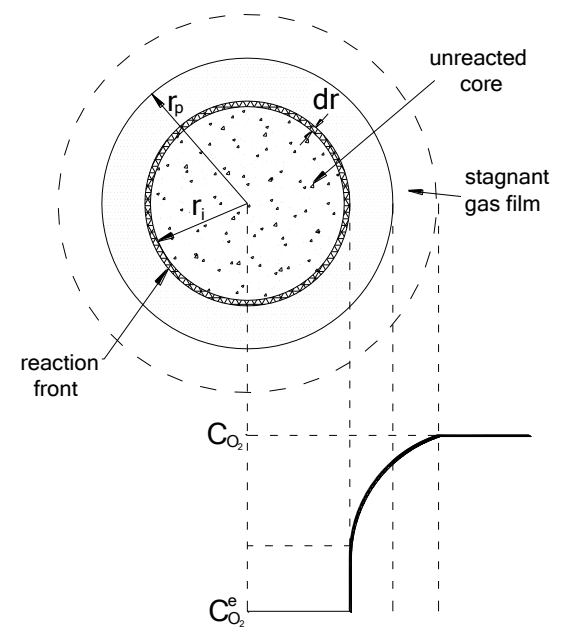

Fig. 2- Schematic of the topochemical reaction progress model 


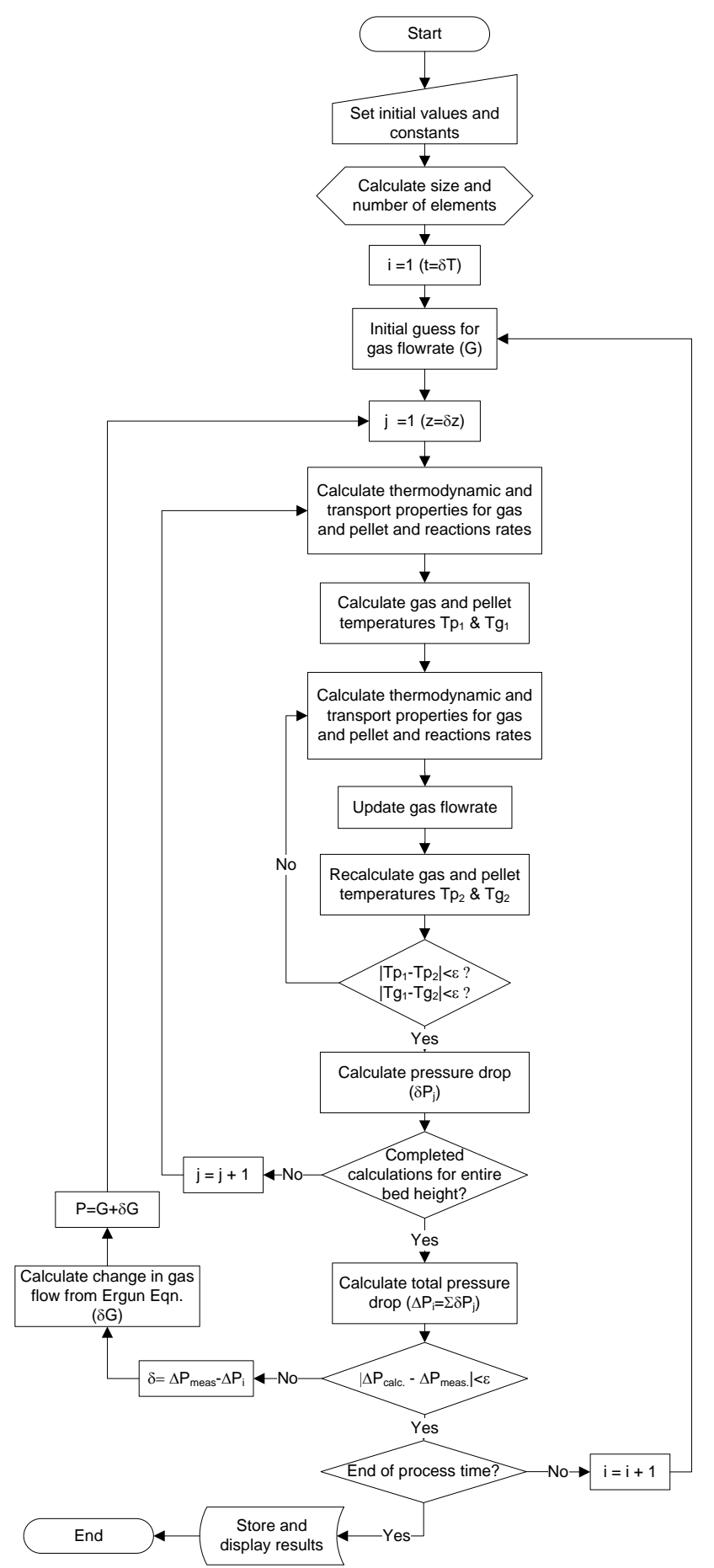

Fig. 3- Flowchart of the solution procedure 

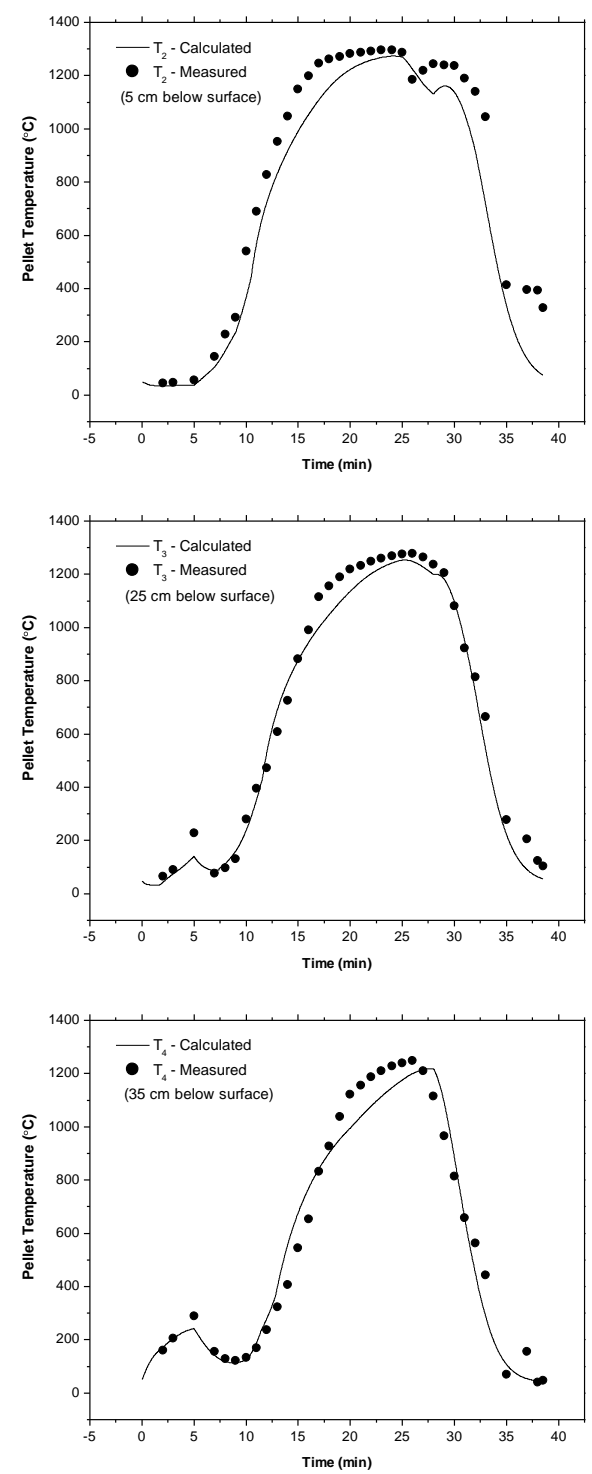

Fig. 4- Comparison between measured and predicted temperature profiles in a pilot induration test

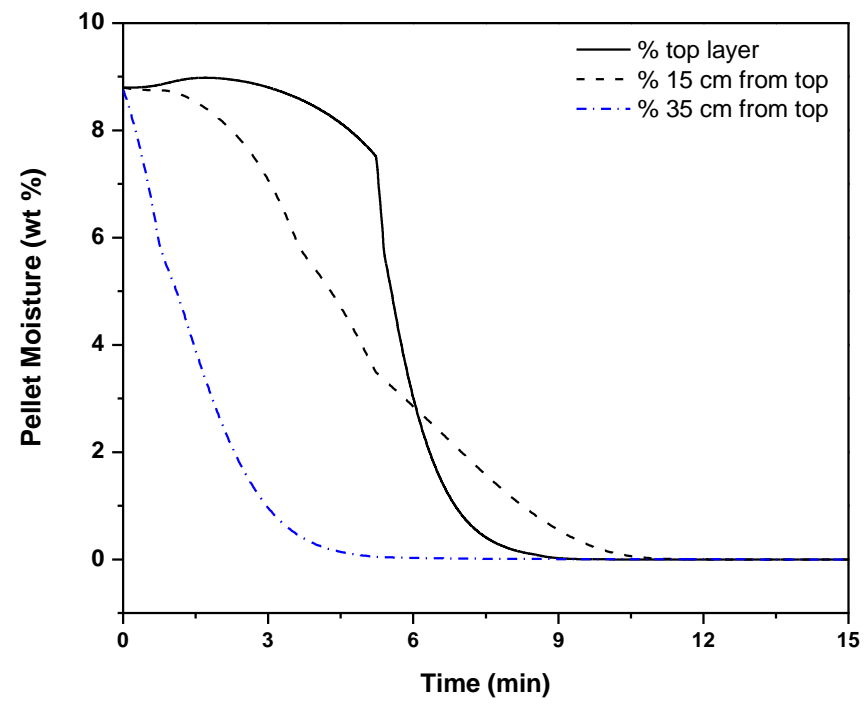

Fig. 5- Drying profile of pellet in different depths of the bed 

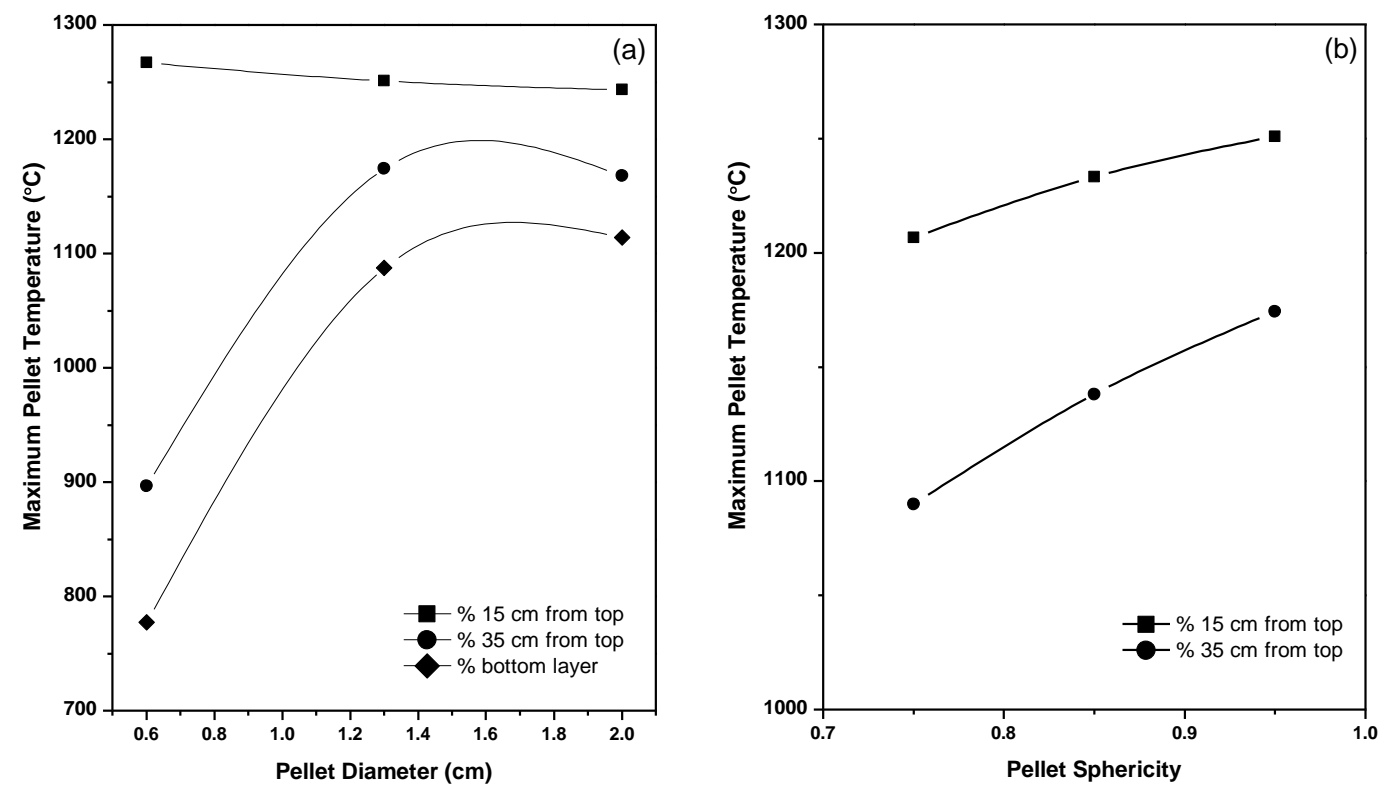

Fig. 6- Effect of (a) pellet size and (b) pellet sphericity on the maximum pellet temperature

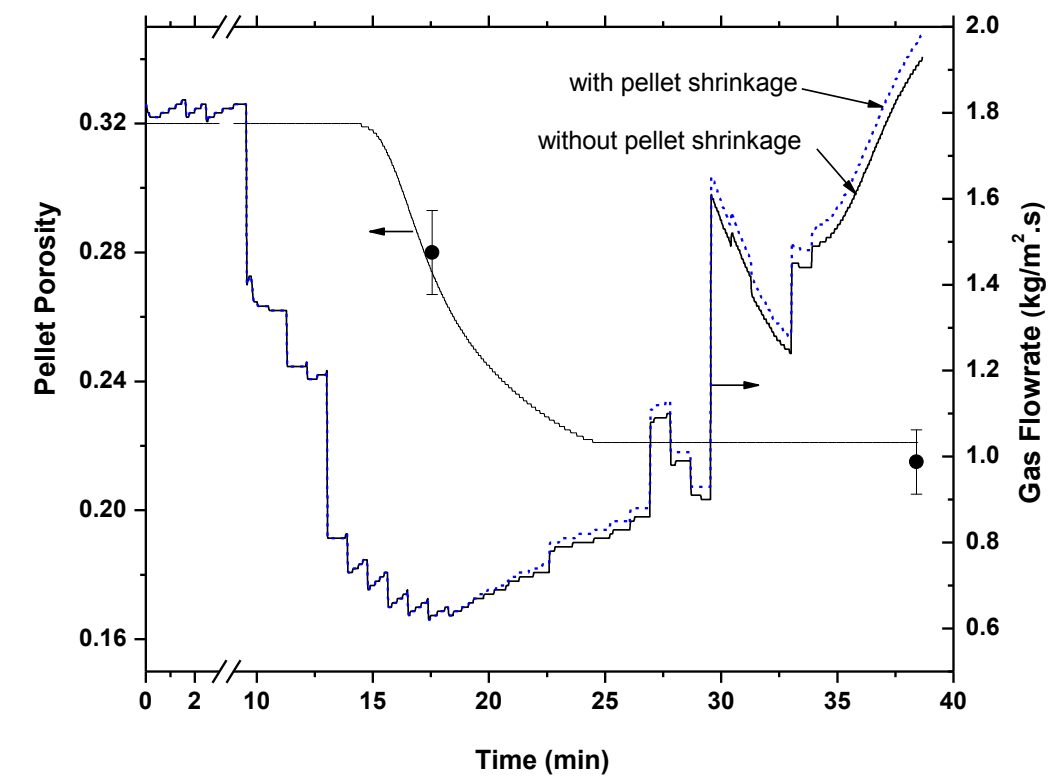

Fig. 7- Variations of pellet porosity with induration time and the effect of porosity on the gas flowrate 


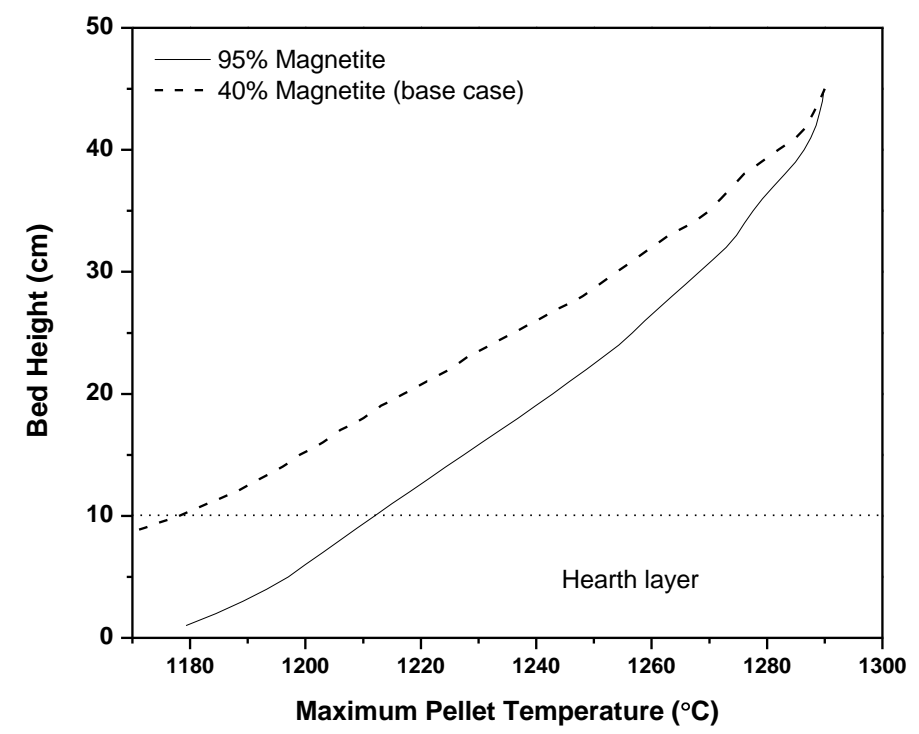

Fig. 8- Effect of pellet feed magnetite content on the bed temperature profile

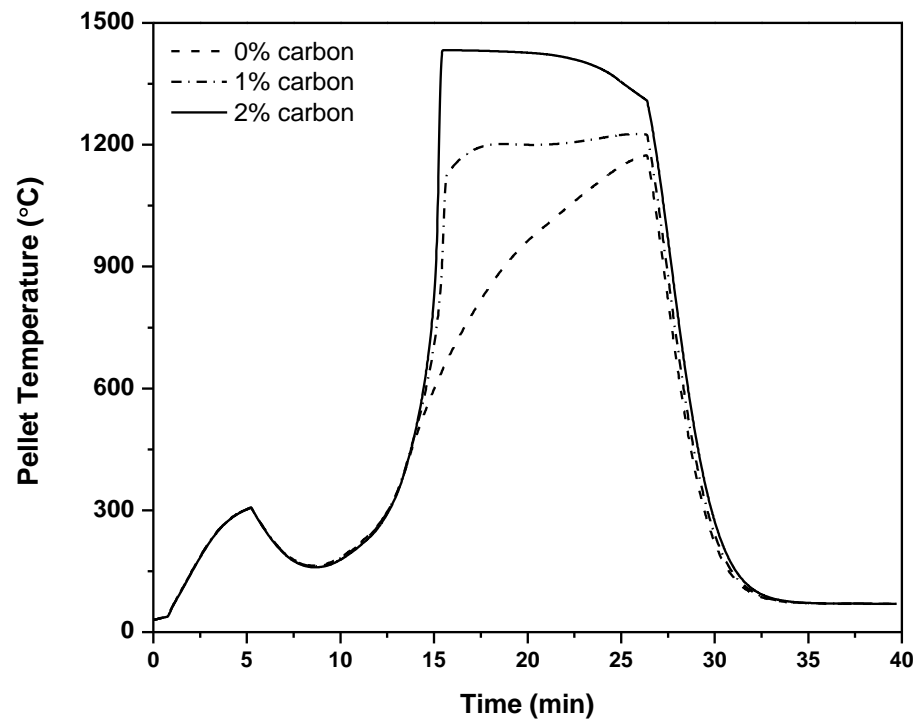

Fig. 9- Effect of carbon addition on the temperature profile of pellet layer just above the heart layer 


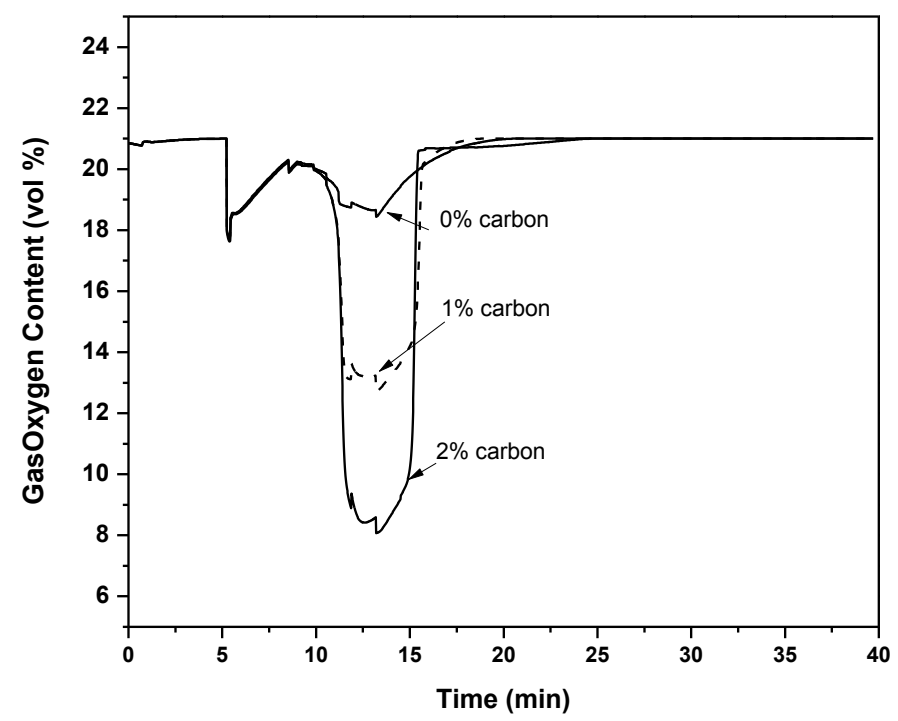

Fig. 10- Oxygen content of the gas versus time in a layer just above the heart layer

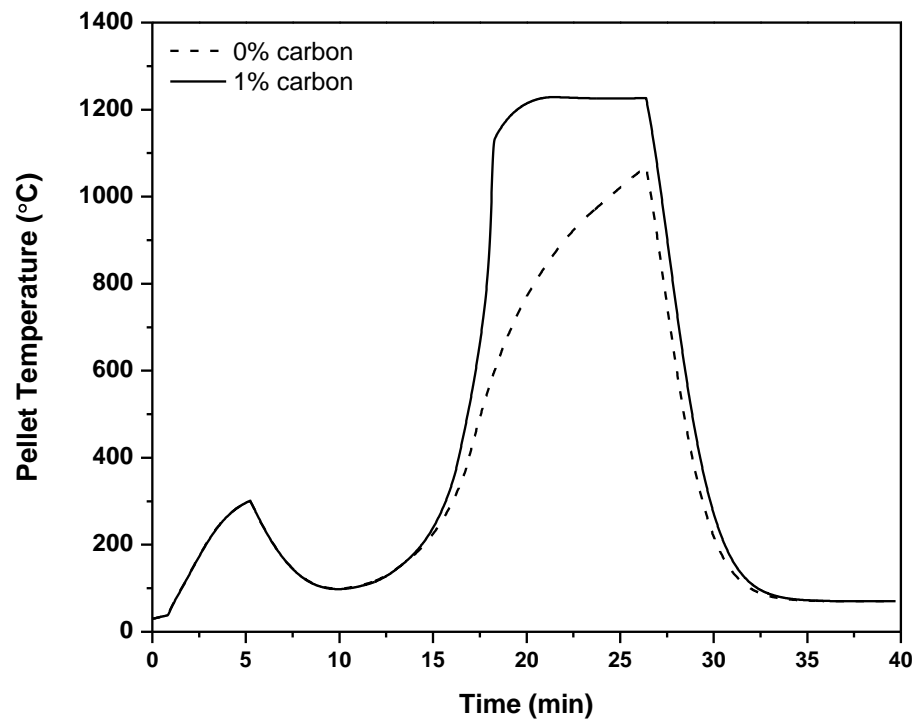

Fig. 11- Effect of carbon addition on temperature of pellet layer $45 \mathrm{~cm}$ below the surface of a $55 \mathrm{~cm}$ pellet bed 